\title{
Overweight and obesity in children with congenital heart disease: combination of risks for the future?
}

\author{
Sandra Mari Barbiero ${ }^{1}$, Caroline D’Azevedo Sica', Daniela Schneid Schuh', Claudia Ciceri Cesa', \\ Rosemary de Oliveira Petkowicz ${ }^{2}$ and Lucia Campos Pellanda ${ }^{1,3^{*}}$
}

\begin{abstract}
Background: Children who have unhealthy lifestyles are predisposed to develop hypertension, dyslipidemia and other complications. The epidemic of obesity is also affecting children with congenital heart disease. The aim of this study is to estimate the prevalence of obesity and describe associated risk factors, including family history in children with congenital heart disease.

Methods: A cross-sectional study with 316 children and adolescents with congenital heart disease seen in an outpatient clinic of a reference hospital. Collected sociodemographic data included family history of chronic disease, dietary habits, laboratory tests (total cholesterol, HDL and LDL/cholesterol, triglycerides, fasting glucose, CRP, hematocrit and hemoglobin), and anthropometric assessment. Anthropometric data of the caregivers was self-reported.
\end{abstract}

Results: The prevalence of excess weight was $26.9 \%$. Altered levels of total cholesterol were observed in $46.9 \%$, of $\mathrm{HDL}$ in $32.7 \%$, LDL in $23.6 \%$ and of triglycerides levels in $20.0 \%$. A higher frequency of family history of obesity (42.6\%; $p=0.001)$, dyslipidemia (48.1\%; $p=<0.001$ ), diabetes (47.4\%; $p=0.002)$, hypertension $(39.2 \% ; p=0.006)$ and ischemic disease (43.7\%; $p=0.023)$, as well as significantly higher values of triglycerides $(p=0.017)$, glycemia $(p=0.004)$ and $C$-reactive protein $(p=0.002)$ were observed among patients with excess weight.

Conclusion: The presence of modifiable risk factors and the variables associated to excess weight in this population was similar to that described in the literature for children without congenital disease. As these children already present the risks associated to heart disease, it is particularly important to promote a healthy lifestyle in this group.

Keywords: Child, Adolescent, Congenital heart disease, Overweight, Ischemic disease

\section{Background}

During the last three decades, there has been a considerable increase in the prevalence of obesity in children and adolescents (4-18 year-old) worldwide [1-3]. Children and adolescents with unhealthy lifestyles are predisposed to develop hypertension, dyslipidemia and other complications [4]. These factors, as well as physical inactivity,

\footnotetext{
* Correspondence: lupellanda@gmail.com

'Post-Graduation Program in Health Sciences: Cardiology, Instituto de Cardiologia/Fundação Universitária de Cardiologia, Porto Alegre, Brazil ${ }^{3}$ Universidade Federal de Ciências da Saúde de Porto Alegre, Avenida Princesa Isabel, 370, Santana, Postal Code: 90620-000 Porto Alegre, RS, Brazil Full list of author information is available at the end of the article
}

may track into adulthood [5] and increase the risk of chronic diseases such as atherosclerosis [1].

The epidemic of obesity is also affecting children with congenital heart disease (CHD). More than one quarter of this population is already overweight [6,7]. Two main causes have been described: physical activity restrictions and interventions for weight gain in infancy, when many lesions cause undernutrition [5]. These interventions often include consumption of increased calories and foods with high fat and sodium content $[8,9]$. Although nutritional requirements and physical functional capacity change as these children grow older and their heart lesions are successfully treated, the inappropriate dietary 
behaviors and physical inactivity are frequently maintained across childhood [10]. The family frequently influences these unhealthy behaviors, both directly, restricting physical activity, for example, and indirectly, by setting an unhealthy model. When parents are obese, as one example, the risk of obesity in their children is increased [11-14].

Therefore, the objective of the present study was to estimate the prevalence of overweight, obesity and associated physical activity habits, passive smoking, glycemia and lipids in children with congenital heart disease. We also sought to investigate cardiovascular risk factors present in children's families.

\section{Methods}

We conducted a cross-sectional study of 316 patients with congenital heart disease, aged between 2 and 18 years, and receiving outpatient care at the Pediatric Cardiology Outpatient Clinic of a referral hospital between September 2010 and March 2013. The study protocol was approved by the Institutional Research Ethics Committee of Instituto de Cardiologia do Rio Grande do Sul, Brazil (4470/2010).

Patients who had innocent murmur, clinical conditions that prevented anthropometric assessment (wheelchair users, malformation of the lower limbs, etc.), genetic syndromes or children without a diagnosis of structural heart disease were excluded from the study.

Data collection was performed according to a weekly list of patients scheduled for routine outpatient visits. Based on this list, the children's guardians were contacted by telephone, and the patients were invited to participate in the study. Those who accepted to participate were asked to fast for 12 hours before laboratory tests. Patients who could not be reached by phone were invited to participate during the medical visit, and their laboratory tests were scheduled for another day.

All patients and guardians received information about the study and, after accepting to participate, signed the written consent form. Next, patients underwent collection of blood samples and anthropometric assessment. The participants' caregivers present during data collection provided information about family risk factors and physical activity habits (International Physical Activity Questionnaire-IPAQ short version) [15]. Data were collected using a questionnaire administered by health professionals who attended two specific training sessions and received training updates regularly. After being assessed, participants who showed abnormal results were referred to multidisciplinary outpatient care for prevention and treatment of risk factors.

Weight was measured to the nearest $0.1 \mathrm{~kg}$ and height to the nearest centimeter using a Welmy electronic digital scale with stadiometer, with $200 \mathrm{Kg}$ capacity, with the child standing, without shoes or heavy clothing. Nutritional status was based on body mass index (BMI), and classified using the software WHO Anthro and Anthro Plus. Cutoff points for underweight/normal weight ( $<85$ th percentile) and excess weight ( $>85$ th percentile being overweight 85th -95 th percentile and obesity $>95$ percentile) for BMI values were used according to the WHO-2006/ 2007 [16].

Blood was collected by peripheral venous puncture after $12 \mathrm{~h}$ fasting. The hematocrit and hemoglobin were determined using whole blood collected with ethylenediaminetetraacetic acid (EDTA), in an automated analyzer (Coulter Act, Coulter, USA). Biochemical analysis of total cholesterol, LDL, HDL cholesterol and triglycerides were determined in serum obtained by centrifugation of blood samples, through enzymatic method on an automated analyzer (Selectra E, Vital Scientific, USA), using reagent kits and protocols according to instructions of the manufacturer. Levels of hs-CRP were determined in serum by nephelometry, using a Behring Nephelomefer 100 Analyzer (Dade Behring, USA).

Blood tests were considered abnormal according to the U.S. pediatric guidelines (2011) and the I Brazilian Guidelines for Prevention of Atherosclerosis in Childhood and Adolescence (2005): total cholesterol $>170 \mathrm{mg} / \mathrm{dL}$, $\mathrm{HDL} /$ cholesterol < $45 \mathrm{mg} / \mathrm{dL}$, LDL/cholesterol $>110 \mathrm{mg} / \mathrm{dL}$, triglycerides $>75 \mathrm{mg} / \mathrm{dL}$ ( $2-9$ years) or $>90 \mathrm{mg} / \mathrm{dL}(10-18$ years) [17], fasting glucose $>100 \mathrm{mg} / \mathrm{dL}, \mathrm{CRP}>0.30 \mathrm{mg} / \mathrm{dL}$, hematocrit $<35 \%$, and hemoglobin $<11.0 \mathrm{~g} / \mathrm{dL}$ [18].

Sample size was estimated as 250 children and adolescents, based on the prevalence of obesity observed in a previous study [19], with absolute error margins ranging from $3 \%$ to $6 \%$ with a confidence level of $95 \%$.

Data were stored and analyzed using the computer program SPSS, version 17.0. The prevalence rates were expressed as percentages with $95 \%$ confidence intervals. The association between risk factors was assessed using the chi-square test or Fisher's exact test. Differences between the groups with and without risk factors were evaluated using the Student $t$ test or Mann-Whitney test for continuous variables and the chi-square test or Fisher's exact test for categorical variables (gender, total cholesterol, HDL/cholesterol, LDL/cholesterol, triglycerides, hematocrit, hemoglobin, glucose, BMI percentile). Poisson multiple logistic regression analysis was adjusted for family history (obesity, dyslipidemia, diabetes, hypertension, and ischemic heart disease), mother's nutritional status, both parents' nutritional status, and adolescents' age. Statistical significance was set at $\mathrm{p}$-value $\leq 0.05$.

This report is presented as suggested by the STROBE statement: guidelines for reporting observational studies [20].

\section{Results}

A total of 341 patients were interviewed, but 25 did not collect blood and were excluded from analysis, resulting 
in 316 participants . Most participants were male (55.7\%), Caucasian (81.6\%) and aged between 6 and 11 years (43.7\%). The majority had been born at term (83.2\%) and had acyanotic congenital heart disease $(81,1 \%)$. The proportion of passive smoking was reported to be $43.7 \%$ (Table 1).

Family history of cardiovascular risk factors included excess weight in $44.3 \%$, dyslipidemia in $53.8 \%$, diabetes in $49.7 \%$, arterial hypertension in $83.2 \%$, and ischemic disease in $52.2 \%$ (Table 1 ).

Table 1 General characteristics of the population

\begin{tabular}{|c|c|}
\hline Variables & $\mathrm{n}=316(\%)$ \\
\hline Male & $176(55.7)$ \\
\hline White & $258(81.6)$ \\
\hline \multicolumn{2}{|l|}{ Age } \\
\hline Preschool age ( $2-5$ years) & $67(21.2)$ \\
\hline School age (6-11 years) & $138(43.7)$ \\
\hline Adolescents (12-18 years) & $111(35.1)$ \\
\hline Born at term & $263(83.20)$ \\
\hline \multicolumn{2}{|l|}{ Heart disease } \\
\hline \multicolumn{2}{|l|}{ Acyanotic } \\
\hline Ventricular Septal Defect (VSD) & $76(24.1)$ \\
\hline Atrial Septal Defect (ASD) & $61(19.3)$ \\
\hline Miscelaneous & $119(37,7)$ \\
\hline \multicolumn{2}{|l|}{ Cyanotic } \\
\hline Tetralogy of Fallot & $43(13.6)$ \\
\hline Pulmonary Atresia & $6(1.9)$ \\
\hline Miscelaneous & $11(3,4)$ \\
\hline \multicolumn{2}{|l|}{ Father's educational level } \\
\hline Elementary school & $191(68.0)$ \\
\hline High school & $79(28.1)$ \\
\hline Incomplete/Complete higher education & $11(3.9)$ \\
\hline \multicolumn{2}{|l|}{ Mother's educational level } \\
\hline Elementary school & $184(60.7)$ \\
\hline High school & $94(31.0)$ \\
\hline Incomplete/Complete higher education & $25(8.3)$ \\
\hline \multicolumn{2}{|l|}{ Number of siblings } \\
\hline Only child & $67(21.2)$ \\
\hline Siblings & $249(78.8)$ \\
\hline \multicolumn{2}{|l|}{ Positive family history for } \\
\hline Excess weight & $140(44.3)$ \\
\hline Dyslipidemia & $170(53.8)$ \\
\hline Diabetes & $157(49.7)$ \\
\hline Hypertension & $263(83.2)$ \\
\hline Heart disease/ischemia & $165(52.2)$ \\
\hline Presence of smokers in the household & $138(43.70)$ \\
\hline
\end{tabular}

The prevalence of excess weight (BMI $\geq 85$ th percentile) was 26.9\%; of these, $17.4 \%$ were overweight (BMI > P85 $\leq 95)$ and $9.5 \%$ were obese (BMI > P95). Excess weight was more common among boys (60\%). In the group of 6-11 years old, $34.1 \%$ presented with excess weight $(\mathrm{p}=$ 0.009 ). The group of acyanotic congenital heart disease showed $27.7 \%$ of overweight, while in patients with cyanotic lesions the proportion was 23,3 (Table 2).

Regarding physical activity classification, children and adolescents with excess weight were very active in $20 \%$, active in $36.5 \%$ and irregularly active in $40 \%$, while eutrophic children were very active in $19.1 \%$, active in $38.7 \%$ and irregularly active in $35.7 \%(\mathrm{p}=0.802)$.

There were 165 mothers $(52,2 \%)$, and 92 fathers $(29,1 \%)$ with excess weight. Mothers' and both parents' excess weight was significantly associated with children's excess weight ( $\mathrm{p}=0.003$ and 0.049 , respectively). The Prevalence Ratio of an excess weight mother to have an excess weight child was 1.24 (CI 1.08-1.43).

As shown in Table 3, the excess weight group had more often a positive family history (first degree relative) for obesity $(\mathrm{p}=0.002)$, dyslipidemia $(\mathrm{p}=<0.001)$, diabetes $(\mathrm{p}=0.005)$, hypertension $(\mathrm{p}=0.010)$, and ischemic disease $(p=0.040)$. The prevalence ratio for excess weight in children was 1.92 (CI $1.22 \pm 3.02, \mathrm{p}=0.005)$ when the mother had excess weight and 1.74 (CI 1.15 \pm 2.62 ; $\mathrm{p}=0.009$ ) when there was a positive family history for dyslipidemia.

Table 4 presents the laboratory tests results, showing that $32.7 \%$ had low HDL, $18.4 \%$ had high total cholesterol, $11.4 \%$ had high LDL, and $32.0 \%$ had increased triglycerides. The excess weight group had significantly higher triglycerides $(\mathrm{p}=0.017)$, glucose $(\mathrm{p}=0.004)$, and $\mathrm{C}$-reactive protein $(\mathrm{p}=0.002)$.

\section{Discussion}

The present study reports a high prevalence of excess weight in children and adolescents with congenital heart disease. Aditionally, we observed a high frequency of excess weight in parents and a positive family history for chronic non-transmissible diseases.

The prevalence of overweight and obesity in children with congenital heart disease was similar to that described in the literature for children with non-congenital disease $[19,21]$ In a population of patients with congenital heart disease in the U.S., researchers found a prevalence of more than $25 \%$ of obese and overweight children [22]. However, in a study published six years ago, the excess weight rate of a population of children and adolescents in Belgium was 7.6\% [11].

In Brazil, the high prevalence of excess weight in children and adolescents in general has been a reason for concern, because other associated risk factors for ischemic heart disease, such as hypertension, glucose 
Table 2 Distribution of general characteristics of the population according to the BMI classification of individuals with congenital heart disease

\begin{tabular}{|c|c|c|c|c|c|c|}
\hline Variables & Total $316(\%)$ & Underweight/Normal weight 231 (\%) & Excess weight 85 (\%) & PR & $\mathrm{Cl}(95 \%)$ & $\mathbf{p}$ \\
\hline Male & $176(55.7)$ & $125(54.1)$ & $51(60)$ & 1,20 & $0.84-1.74$ & 0.321 \\
\hline Only child & $67(21.2)$ & $49(21.2)$ & $18(21.2)$ & 1.0 & $0.65-1.55$ & 0,99 \\
\hline Preterm birth & $49(15.5)$ & $31(13.4)$ & $18(21.2)$ & 1.53 & $1.01-2.32$ & 0.046 \\
\hline \multicolumn{7}{|l|}{ Age } \\
\hline Preschool age ( $2-5$ years) & $67(21.2)$ & $57(24.7)$ & $10(11.8)$ & 1.0 & - & - \\
\hline School age (6-11 years) & $138(43.7)$ & $91(39.4)$ & $47(55.3)$ & 2.29 & $1.24-4.23$ & 0.008 \\
\hline Adolescent (12-18 years) & $111(35.1)$ & $83(35.9)$ & $28(32.9)$ & 1.71 & $0.89-3.27$ & 0.104 \\
\hline \multicolumn{7}{|l|}{ Congenital heart disease } \\
\hline Cyanotic & $60(19)$ & $46(19,9)$ & $14(16,5)$ & 0,84 & $0,51-1,37$ & 0,48 \\
\hline Acyanotic & $256(81)$ & $185(80,1)$ & $71(83,5)$ & 1,0 & - & - \\
\hline
\end{tabular}

PR: prevalence ratio; $\mathrm{Cl}$ : confidence interval.

intolerance, dyslipidemia, and physical inactivity have emerged [7,23-27].

The presence of modifiable risk factors for ischemic heart disease in this population, such as an abnormal lipid profile (high total cholesterol/LDL/triglycerides, low HDL) and excess weight may lead individuals with congenital heart disease to have a combination of risks that may persist into adulthood $[4,28]$. These modifiable risk factors have been well discussed in the literature about children without heart disease [2,21].

The presence of chronic diseases in families of patients with congenital heart disease is an additional risk factor for ischemic disease $[7,22,28,29]$, similarly to what occurs for healthy children/adolescents [23,30] and adults in general $[31,32]$. The presence of obesity in mothers in our study was directly related to their children's excess weight. This findings could represent both biological/ genetic characteristics and family lifestyles [14,33,34]. In a study comparing three generations of families, there was a strong significant relationship between the BMI of mothers and children, thus suggesting the discussion of inheritance of family patterns and lifestyle, as well as family phenotypes [14]. In another study evaluating the role of parents in the treatment of childhood obesity, the authors found that distorted maternal perception leads mothers to see their children's excess weight as normal, making it difficult for them to admit their children need treatment [34].

In our study, approximately half of children and adolescents were irregularly active or sedentary. In many cases, physical activity may be limited by the parents anxiety [35].

Passive smoking was detected in almost half of the population studied, a rate much higher than in a survey conducted over the past decade, in which more than $25 \%$ of children lived with at least one smoking parent. Exposure to secondhand smoking in children causes higher rates of pneumonia, ear infections, sudden infant death syndrome, asthma, and other negative health effects [36]. In addition, children's airways are more vulnerable, suffering dramatically with the effects of secondhand smoking [37]. Children exposed to tobacco smoke at a young age are more likely to become smokers and continue the cycle of smoking in adulthood [38].

It is important to consider that factors present since the children's conception may contribute to "programming" of disease in adult life $[39,40]$. The quality of the mother's nutrition during pregnancy may affect the fetal

Table 3 Family history of obesity and chronic diseases according to the BMI categories of individuals with congenital heart disease

\begin{tabular}{|c|c|c|c|c|c|c|}
\hline Variables & Total $316(\%)$ & $\begin{array}{l}\text { Underweight/Normal } \\
\text { weight } 231(\%)\end{array}$ & Excess weight 85 (\%) & PR & $\mathrm{Cl}(95 \%)$ & $\mathbf{P}$ \\
\hline \multicolumn{7}{|l|}{ 1st-degree relative with } \\
\hline obesity & $68(21.5)$ & $39(16.9)$ & $29(34.1)$ & 1.26 & $1.07-1.49$ & 0.002 \\
\hline dyslipidemia & $52(16.5)$ & $27(11.7)$ & $25(29.4)$ & 1.25 & $1.08-1.45$ & $<0.001$ \\
\hline diabetes & $38(12.0)$ & $20(8.6)$ & $18(21.2)$ & 1.16 & $1.03-1.3$ & 0.005 \\
\hline hypertension & $74(23.4)$ & $45(19.5)$ & $29(34.1)$ & 1.22 & $1.04-1.44$ & 0.010 \\
\hline heart disease/ischemic disease & $32(10.1)$ & $18(7.8)$ & $14(16.5)$ & 1.1 & $0.99-1.22$ & 0.040 \\
\hline
\end{tabular}

PR: prevalence ratio; $\mathrm{Cl}$ : confidence interval. 
Table 4 Laboratory tests according to the BMI categories of individuals with congenital heart disease

\begin{tabular}{lccc}
\hline Variables & $\begin{array}{c}\text { Underweight/Normal } \\
\text { weight mean } \pm \text { SD }\end{array}$ & $\begin{array}{c}\text { Excess weight } \\
\text { mean } \pm \text { SD }\end{array}$ & $\mathbf{p}$ \\
\hline Cholesterol & $148.1 \pm 25.6$ & $154 \pm 32.2$ & 0.106 \\
HDL & $50.3 \pm 11.3$ & $48.9 \pm 12.2$ & 0.352 \\
LDL & $83.3 \pm 21.7$ & $89.3 \pm 27.8$ & 0.053 \\
Triglycerides & $72.6 \pm 34.3$ & $83.7 \pm 38.8$ & 0.017 \\
Glucose & $87 \pm 9.5$ & $90.6 \pm 9.0$ & 0.004 \\
C-reactive protein & $0.1 \pm 0.1$ & $0.2 \pm 0.2$ & 0.002 \\
Hematocrit & $39.1 \pm 4.1$ & $38.8 \pm 3.4$ & 0.523 \\
Hemoglobin & $13.3 \pm 1.9$ & $12.9 \pm 1.5$ & 0.099 \\
\hline SD: stancard & & &
\end{tabular}

SD: standard deviation.

metabolism and the child's taste and attitudes towards food [41]. Along the life course, these factors interact with family habits and childhood risks to compose different health and disease pathways [14].

The present study has some limitations that deserve to be mentioned. Possible confounding biases may be related to memory bias and underreporting of information by the respondents. Cross-sectional designs do not allow causal inferences or detailed evaluation of sequences of events. Despite these limitations, to the best at our knowledge, this is one of the largest series of patients with congenital heart disease evaluated for these risk in Brazil or other developing countries.

\section{Conclusions}

The obesity epidemic also affects children and adolescents with congenital heart disease. In this population, factors inherent to the heart disease can be added to other traditional risk factors for the development of ischemic heart disease in the future. Changes in the lifestyle are necessary to change these risk factors and its comorbidities in the adult life of these people who are living longer.

\section{Abbreviations}

BMI: Body mass index; CHD: Congenital heart disease; DBP: Diastolic blood pressure; EDTA: Ethylenediaminetetraacetic acid; SBP: Systolic blood pressure.

\section{Competing interests}

The authors declare that they have no competing interests.

\section{Authors' contributions}

SMB: Substantial contributions to conception and design, collection of data, acquisition of data, analysis, interpretation of data and drafting the article. CSG, DSS: Participation in collection of data, acquisition and analysis of data. CCC, ROP: contributions to conception and design, analysis, interpretation of data, revising the article critically for important intellectual content. LCP: Substantial contributions to conception and design, acquisition of funding, analysis, interpretation of data, drafting the article, revising and drafting the article critically for important intellectual content; and final approval of the version to be published. All authors read and approved the final manuscript.

\section{Acknowledgment}

Institute of Cardiology Research Foundation (Fundo de Apoio do Instituto de Cardiologia/FUC à Ciência e Cultura - FAPICC).

\section{Author details}

${ }^{1}$ Post-Graduation Program in Health Sciences: Cardiology, Instituto de Cardiologia/Fundação Universitária de Cardiologia, Porto Alegre, Brazil. ${ }^{2}$ Post-Graduation Program in Human Movement Sciences from the Universidade Federal do Rio Grande do Sul, Porto Alegre, Brazil.

${ }^{3}$ Universidade Federal de Ciências da Saúde de Porto Alegre, Avenida Princesa Isabel, 370, Santana, Postal Code: 90620-000 Porto Alegre, RS, Brazil.

Received: 3 February 2014 Accepted: 15 August 2014

Published: 16 October 2014

\section{References}

1. Kelishadi R, Hashemipour M, Sheikh-Heidar A, Ghatreh-Samani S: Changes in serum lipid profile of obese or overweight children and adolescents following a lifestyle modification course. ARYA Atheroscler 2012, 8:143-148.

2. Gupta N, Goel K, Shah P, Misra A: Childhood obesity in developing countries: epidemiology, determinants, and prevention. Endocr Rev 2012, 33:48-70.

3. Organization WH: Facts and figures on childhood obesity. 2014. http://www. who.int/dietphysicalactivity/end-childhood-obesity/facts/en/ Accessed in 06/26/2014

4. Moons P, Deyk KV, Dedroog D, Troost E, Budts W: Prevalence of cardiovascular risk factors in adults with congenital heart disease. Eur J Cardiovasc Prev Rehabil 2006, 13:612-616.

5. Muller-Riemenschneider F, Nocon M, Willich SN: Prevalence of modifiable cardiovascular risk factors in german adolescents. Eur J Cardiovasc Prev Rehabil 2010, 17:204-210

6. Shustak RJ, McGuire SB, October TW, Phoon CK, Chun AJ: Prevalence of obesity among patients with congenital and acquired heart disease. Pediatr Cardiol 2012, 33:8-14.

7. Cohen MS: Clinical practice: the effect of obesity in children with congenital heart disease. Eur J Pediatr 2012, 171:1145-1150.

8. Hansen SR, Dorup I: Energy and nutrient intakes in congenital heart disease. Acta Paediatr 1993, 82:166-172.

9. Ratanachu-Ek S, Pongdara A: Nutritional status of pediatric patients with congenital heart disease: Pre- and post cardiac surgery. J Med Assoc Thai 2011, 94(Suppl 3):S133-S137.

10. Moola F, Fusco C, Kirsh JA: The perceptions of caregivers toward physical activity and health in youth with congenital heart disease. Qual Health Res 2011, 21(2):278-291. United States.

11. Massin MM, Hövels-Gürich $H$, Seghaye MC: Atherosclerosis lifestyle risk factors in children with congenital heart disease. Eur J Cardiovasc Prev Rehabil 2007, 14:349-351.

12. Martinez-Quintana E, Rodriguez-Gonzalez F, Nieto-Lago V, Novoa FJ, Lopez-Rios L, Riano-Ruiz M: Serum Glucose and Lipid Levels in Adult Congenital Heart Disease Patients. Metabolism. United States: 2010 Elsevier Inc; 2010:1642-1648.

13. Yoshinaga M, Takahashi H, Shinomiya M, Miyazaki A, Kuribayashi N, Ichida F: Impact of having one cardiovascular risk factor on other cardiovascular risk factor levels in adolescents. J Atheroscler Thromb 2010, 17:1167-1175

14. Murrin CM, Kelly GE, Tremblay RE, Kelleher CC: Body mass index and height over three generations: evidence from the lifeways cross-generational cohort study. BMC Public Health 2012, 12:81.

15. Pardini $R$ : Validation of the international physical activity questionaire (ipaq version 6): Pilot Study in brazilian young adults. Rev Bras Ciên e Mov 2001, 9:45-51.

16. De Onis M, World Health Organization, Dept. of Nutrition for Health and Development: Who Child Growth Standards. Methods and Development Length/Height-for-age, Weight-for-age, Weight-for-Length, Weight-for-Height and Body Mass Index-for-age. Geneva: 2006.

17. Expert panel on integrated guidelines for cardiovascular health and risk reduction in children and adolescents: summary report. Pediatrics 2011, 128(Suppl 5):S213-S256.

18. Back Giuliano Ide C, Caramelli B, Pellanda L, Duncan B, Mattos S, Fonseca FH, Sociedade Brasileira de Cardiologia: I diretriz de prevenção da aterosclerose na infância e na adolescência. Arq Bras Cardiol 2005, 85:S4-S36. 
19. Barbiero SM, Pellanda LC, Cesa CC, Campagnolo P, Beltrami F, Abrantes CC: Overweight, obesity and other risk factors for ind in brazilian schoolchildren. Public Health Nutr 2009, 12(5):710-715. England.

20. Elm E, Altman D, Egger M, Pocock S, Gotzsche P: the strengthening the reporting of observational studies in epidemiology (strobe) statement: Guidelines for reporting observational studies. 2007, 370:1453-1457.

21. Messiah SE, Arheart KL, Natale RA, Hlaing WM, Lipshultz SE, Miller TL: Bmi, waist circumference, and selected cardiovascular disease risk factors among preschool-age children. Obesity (Silver Spring) 2012, 1942-1949. United States.

22. Pinto NM, Marino BS, Wernovsky G, de Ferranti SD, Walsh AZ, Laronde M, Hyland K, Dunn SO, Cohen MS: Obesity is a common comorbidity in children with congenital and acquired heart disease. Pediatrics 2007, 120:e1157-e1164.

23. Glowinska B, Urban M, Koput A: Cardiovascular risk factors in children with obesity, hypertension and diabetes: Lipoprotein(a) levels and body mass index correlate with family history of cardiovascular disease. Eur J Pediatr 2002, 161:511-518.

24. Update on the 1987 task force report on high blood pressure in children and adolescents: A working group report from the national high blood pressure education program. National high blood pressure education program working group on hypertension control in children and adolescents. Pediatrics 1996, 98:649-658.

25. Pall D, Kiss I, Katona E: Importance of ambulatory blood pressure monitoring in adolescent hypertension. Kidney Blood Press Res 2012, 35(2):129-134. Switzerland: Basel.

26. Tremblay MS, LeBlanc AG, Kho ME, Saunders TJ, Larouche R, Colley RC, Goldfield G, Connor Gorber S: Systematic review of sedentary behaviour and health indicators in school-aged children and youth. Int J Behav Nutr Phys Act 2011, 98:8. England.

27. Rivera IR, Silva MA, Silva RD, Oliveira BA, Carvalho AC: Physical inactivity, tv-watching hours and body composition in children and adolescents. Arq Bras Cardiol 2010, 95:159-165.

28. Massin M: the cardiovascular risk in children with congenital heart disease. Arch Mal Coeur Vaiss 2007, 100(5):448-453. France.

29. Pasquali SK, Marino BS, Pudusseri A, Wernovsky G, Paridon SM, Walker SA, Cohen MS: Risk factors and comorbidities associated with obesity in children and adolescents after the arterial switch operation and ross procedure. Am Heart J 2009, 158:473-479.

30. Costa Silva Zemdegs J, Barreto Corsi L, De Castro Coelho L, Duarte Pimentel G, Toyomi Hirai A, Sachs A: Lipid profile and cardiovascular risk factors among first-year brazilian university students in são paulo. Nutr Hosp 2011, 26:553-559.

31. Dwivedi S, Aggarwal A: Central obesity, hypertension and coronary artery disease: the seed and soil hypothesis. World J Cardiol 2011, 3:40-42.

32. Roche SL, Silversides CK: Hypertension, obesity, and coronary artery disease in the survivors of congenital heart disease. Can J Cardiol 2013.

33. Sonneville KR, Rifas-Shiman SL, Kleinman KP, Gortmaker SL, Gillman MW, Taveras EM: Associations of obesogenic behaviors in mothers and obese children participating in a randomized trial. Obesity (Silver Spring) 2012, 20:1449-1454.

34. Camargo AP, Barros Filho Ade A, Antonio MA, Giglio JS: the non perception of obesity can be an obstacle to the role of mothers in taking care of their children. Cien Saude Colet 2013, 18:323-333.

35. Pemberton VL, McCrindle BW, Barkin S, Daniels SR, Barlow SE, Binns HJ, Cohen MS, Economos C, Faith MS, Gidding SS, Goldberg CS, Kavey RE, Longmuir P, Rocchini AP, Van Horn L, Kaltman JR: Report of the national heart, lung, and blood institute's working group on obesity and other cardiovascular risk factors in congenital heart disease. Circulation 2010, 121:1153-1159.

36. Hipple B, Nabi-Burza E, Hall N, Regan S, Winickoff JP: Distance-based training in two community health centers to address tobacco smoke exposure of children. BMC Pediatr 2013, 56:13.

37. Coelho SA, Rocha SA, Jong LC: Consequências do tabagismo passivo em crianças. Cienc Cuid Saude 2012, 11:294-301.

38. Pandey AKP, Pandey S, Blaha MJ, Agatston A, Feldman T, Ozner M, Santos RD, Budoff MJ, Blumenthal RS, Nasir K: Family history of coronary heart disease and markers of subclinical cardiovascular disease: Where do we stand? Atherosclerosis 2013, 228(2):285-294.
39. Reilly JJ, Armstrong J, Dorosty AR, Emmett PM, Ness A, Rogers I, Steer C, Sherriff A: Early life risk factors for obesity in childhood: Cohort study. BMJ 2005, 330:1357.

40. Vickers MH: Developmental programming of the metabolic syndrome - critical windows for intervention. World J Diabetes 2011, 2:137-148.

41. Heerwagen MJ, Miller MR, Barbour LA, Friedman JE: Maternal obesity and fetal metabolic programming: a fertile epigenetic soil. Am J Physiol Regul Integr Comp Physiol 2010, 299:R711-R722.

doi:10.1186/1471-2431-14-271

Cite this article as: Barbiero et al:: Overweight and obesity in children with congenital heart disease: combination of risks for the future? BMC Pediatrics 2014 14:271.

\section{Submit your next manuscript to BioMed Central and take full advantage of:}

- Convenient online submission

- Thorough peer review

- No space constraints or color figure charges

- Immediate publication on acceptance

- Inclusion in PubMed, CAS, Scopus and Google Scholar

- Research which is freely available for redistribution

Submit your manuscript at www.biomedcentral.com/submit
C BioMed Central 